Erratum

\title{
Erratum: Catechol-Based Hydrogel for Chemical Information Processing. Biomimetics 2017, 2, 11
}

\author{
Eunkyoung Kim ${ }^{1,2} \mathbb{D}^{\mathbb{D}}$, Zhengchun Liu ${ }^{3}$, Yi Liu ${ }^{1,2}$, William E. Bentley ${ }^{1,2}$ and \\ Gregory F. Payne ${ }^{1,2, *}$ \\ 1 Institute for Biosystems and Biotechnology Research, University of Maryland, 5115 Plant Sciences Building, \\ College Park, MD 20742, USA; ekim@umd.edu (E.K.); yliu123@umd.edu (Y.L.); bentley@umd.edu (W.E.B.) \\ 2 Fischell Department of Bioengineering, University of Maryland, College Park, MD 20742, USA \\ 3 Hunan Key Laboratory for Super Microstructure and Ultrafast Process, School of Physics and Electronics, \\ Central South University, Changsha 410083, China; liuzhengchunseu@126.com \\ * Correspondence: gpayne@umd.edu; Tel.: +301-405-8389; Fax: +301-314-9075
}

Received: 3 May 2018; Accepted: 7 May 2018; Published: 7 May 2018

It was brought to our attention that there were errors in the original publication by Kim et al. [1].

1. One of the authors' names was misspelled, "Zhenchun" has been corrected to "Zhengchun".

2. In Reference 102, the author's names and last names were inadvertently switched,

"Yi, L.; Eunkyoung, K.; Reza, G.; Gary, W.R.; James, N.C.; William, E.B.; Gregory, F.P. Biofabrication to build the biology-device interface. Biofabrication 2010, 2, 022002."

has been corrected to

"Liu, Y.; Kim, E.; Ghodssi, R.; Rubloff, G.W.; Culver, J.N.; Bentley, W.E.; Payne, G.F. Biofabrication to build the biology-device interface. Biofabrication 2010, 2, 022002."

We apologize for this error.

\section{Reference}

1. Kim, E.; Liu, Z.; Liu, Y.; Bentley, W.E.; Payne, G.F. Catechol-based hydrogel for chemical information processing. Biomimetics 2017, 2, 11. [CrossRef] 